\title{
The integrated indicator of sustainable urban development based on standardization
}

\author{
Tatiana Leonova ${ }^{1}$, Irina Golovtcova ${ }^{1,{ }^{*}}$, Eitiram Mamedov ${ }^{1}$ and Maria Varfolomeeva $^{1}$ \\ ${ }^{1}$ St. Petersburg State University of Economics, Department of Economics and Quality Management, \\ 21, Sadovaya street, 191023, St. Petersburg, Russia
}

\begin{abstract}
The paper justifies the necessity for the system of planned indicators for sustainable urban development design in accordance with the requirements of international standards and the Russian standard GOST R ISO 37120-2015, and the estimation of their actual achievement based on complex qualimetric models. An analysis of opinions on this issue and an overview of Russian normative documents for assessing the effectiveness of the municipalities, including urban development are presented. General methodological principles and sequence for the construction of qualimetric models, as well as formulas for the calculation of complex indicators, taking into account the specific weights obtained on the basis of expert assessment, are presented, the need for careful selection of experts and determination of the consistency of expert opinions is indicated. The advantages and disadvantages of this approach are shown. Conclusions are drawn on the use of qualimetric models for sustainable urban development.
\end{abstract}

\section{Introduction}

The problem of forming the system of target indicators for urban sustainable development is quite urgent, in connection with the fact that such a system sets the benchmark for development and should be the basis for socio-economic forecasts and urban development plans.

The study is aimed at the justification of the need for the application of a system of indicators for urban planning based on international standardization, as well as the formation of a complex indicator necessary for assessing the level of development, the formation of ratings and finding the areas for improvement.

The history of the indicator system for the urban sustainable development formation is quite vast. Initially, on the initiative of the World Bank, the task to justify the indicators of territory sustainable development was entrusted to specialists in the field of regional development in Canada. Normative legal documents that were operating at the international level were considered during the development of the indicators. Among these documents, such standards as "The United Nations. Indicators of sustainable development: principles and methodology", "UN Statistics Division. Environment. Glossary", etc. [1, 2]. The logical continuation of scientific development was the creation of the draft international standard "Sustainable development of society - indicators on urban services and the quality of life."

* Corresponding author: golovtsova@mail.ru 
The International Organization for Standardization (ISO) created a new technical committee (TC) ISO / TC 268 "Sustainable development in communities" in the beginning of 2012. The TC is directed primarily at the development of criteria for assessing the performance of community management bodies and the creation of community management systems. In this context, the community is an administrative-territorial entity whose goal is to ensure the safety and favorable conditions of human life, to provide the protection and rational use of natural resources in the interests of present and future generations, and to limit the negative impact of economic and other activities on the environment. Thus, the community can be considered as a region, a city, and a municipal entity [3].

The Technical Committee 268 developed the international standard ISO 37120: 2014 "Sustainable development of society - indicators for urban services and the quality of life of the population", GOST R ISO 37120-2015 is designed according to this standard. The standard indentifies 17 areas that have potential to contribute simultaneously to the vast estimation of the quality of life and can be used to assess the competitiveness of the territory. For example, there are such indicators as the concentration of small solid particles, noise pollution, greenhouse gas emissions, the number of connections to the Internet for 10 thousand people, the number of connections from mobile phones per 100 thousand people, etc. [4].

The indicators measuring the effectiveness of the territory and city development in the Russian Federation are reflected in many normative state documents such as:

1. The Decree of the President of the Russian Federation, November 14, 2017 - No. 548 "The evaluation of the effectiveness of the executive bodies of subjects of the Russian Federation," that contains 24 indicators for assessing the effectiveness of the executive authorities of the constituent entities of the Russian Federation, only 14 indicators correspond with the indicators of sustainable development (GOST R ISO 37120-2015).

2. Decree of the President of the Russian Federation No. 607 of April 28, 2008 (Ed. $04 / 11 / 2016$ ) "On the evaluation of the effectiveness of local self-government bodies of city districts and municipal districts", that approved a list of indicators for assessing the effectiveness of local self-government authorities in urban and municipal districts and contains only 12 indicators, not reflecting an objective assessment of the effectiveness of the local government activities and has 7 indicators corresponding with the indicators of sustainable development (GOST R ISO 37120-2015).

3. Decree of the Government of the Russian Federation No. 1317, December 17, 2012 (Ed. 02/06/2017) "On measures to implement the Decree of the President of the Russian Federation, April 28, 2008 No. 607 and subparagraph "I" of paragraph 2 of the Decree of the President of the Russian Federation, May 7, 2012 No. 601 "On Main Directions for the Improvement of the Public Administration System" that contains the list of additional indicators separated into 8 groups that include 27 different indicators, but only 17 indicators are similar to the indicators of GOST R ISO 37120-2015.

4. Additional expanded annex of Resolution of the Government of the Russian Federation No. 1317 dated December 17, 2012, that contains indicators of the effectiveness of local selfgovernment bodies of the urban districts (municipal districts), whose achieved and planned performance indicators (for a 3-year period) should be reported by the heads of local administrations of urban and municipal districts in the current year. The list has 39 indicators, among them 25 indicators correspond the list of GOST R ISO 37120-2015.

5. Resolution of the Government of the Russian Federation, November 3, $2012 \mathrm{~N} 1142$ "On measures to implement the Decree of the President of the Russian Federation of August 21, 2012 N 1199 "On assessing the effectiveness of the executive authorities of the constituent entities of the Russian Federation" (Ed. 26/11/2015), where 11 indicators are considered to cover about $20 \%$ of the indicators presented in GOST R ISO 37120-2015. 
Thus, the Russian regulatory documents do not complexly reflect all indicators of sustainable development. It should also be noted that none of the listed regulatory documents contains indicators related to the ecology and the environment, as well as the elimination of fires and emergencies. Burak P.I. and Zvorykina T.I. emphasize that the indicators in the proposed international standard are more specific and sophisticated and accumulate information on administrative and territorial entities of the whole world [5]. Thus, along with the indicators adopted in Russia at the state level, the standard contains environmental indicators absent in the domestic reporting data, such as the concentration of fine particulate matter (PM 2.5), the concentration of particulate matter (PM10), noise pollution, emissions of greenhouse gases in tons per capita, etc. The standard contains a set of indicators that characterizes telecommunications and innovation activities, for example: the number of connections to the Internet network for 10,000 people, the number of connections from mobile phones per 100,000 people, etc. [5].

However, there are positive changes in the standardization development, it is necessary to mention there are still no methodological approaches for applying the system of indicators for making strategic and tactical decisions aimed at the improving the quality of life and sustainable development. To date, a set of standardized indicators should be a priority to help regions and cities:

$\checkmark$ correctly apply the data of comprehensive development for making decisions to improve the quality of life;

$\checkmark$ compare the results of the activities in different regions both in Russia and abroad;

$\checkmark$ establish new criteria for planning its activities;

$\checkmark$ provide cooperation on financing with the federal authorities;

$\checkmark$ create and support the concept of sustainable development in administrative-territorial units and cities.

Thus, it is possible to conclude that, the shift to the management of regions from a position of standardization, which includes the most progressive international experience in order to achieve sustainable development is of high importance $[5,6,7,8,9,10]$.

\section{Methods}

In general, the assessment of the level of sustainable development should be based on a comprehensive assessment, that includes the formation of the qualimetric model and the justification of indicators' specific weights.

Science qualimetry, as one of the directions of the Total Quality Management (TQM), is designed to quantify the quality of any objects and phenomena, regardless their essence [69]. The use of qualimetric approaches in assessing the quality of an object makes it possible to measure various qualitative parameters of the object, to determine complex indicators, and also to compare parameters with other objects, to design ratings etc.

The general methodology of qualimetric assessment of the object quality includes following stages: representation of the object quality, as a structured set of properties (hierarchy); the creation of measurable parameters for each property, by setting the scales for measuring parameters, selecting the baseline indicators; the design of single indicators of the object properties; the establishment of the specific significance of single indicators; compilation of a complex indicator.

In general, an assessment of the level of sustainable urban development should be made on the basis of a comprehensive assessment, that includes the design of a qualimetric model and the justification of specific indicators' weights.

The paper proposes a comprehensive model based on GOST R ISO 37120-2015 indicators and can be represented in the following form (1): 


$$
\begin{gathered}
K=a 1 \cdot P_{1}+a 2 \cdot P_{2}+a 3 \cdot P_{3}+a 4 \cdot P_{4}+a 5 \cdot P_{5}+a 6 \cdot P_{6}+a 7 \cdot P_{7}+ \\
+a 8 \cdot P_{8}+a 9 \cdot P_{9}+a 10 \cdot P_{10}+a 11 \cdot P_{11}+a 12 \cdot P_{12}+a 13 \cdot P_{13}+a 14 \cdot P_{14}+ \\
+a 15 \cdot P_{15}+a 16 \cdot P_{16}+a 17 \cdot P_{17}
\end{gathered}
$$

where $P_{i}$ - standard 17 indicators GOST R ISO 37120-2015.

According to the authors' opinion, the indicators included in the model are of different significance, at the same time, the establishment of specific weights is an important task that can be solved on the basis of expert judgment.

The weight coefficient can be determined by the formula:

$$
\mathrm{a}_{\mathrm{i}}=\sum_{\mathrm{i}=1}^{\mathrm{n}} \mathrm{S}_{\mathrm{ij}} /\left(\sum_{\mathrm{i}=1}^{\mathrm{n}} \sum_{\mathrm{j}=1}^{\mathrm{m}} \mathrm{S}_{\mathrm{ij}}\right)
$$

where ai - the of specific weight of the i-th index;

$\mathrm{Sij}$ - determined scores (scored according to the rank) for the indicator on the $\mathrm{j}$-th indicator, assigned by the i-th expert.

It is especially necessary to note the problem of selecting experts, whose opinion has an impact on specific weights. The experts of the state committees for strategic development and specialists - scientists, engaged in research on this issue were involved in the expert commission for the design of the sustainable urban development assessment.

Table 1. An application form for calculation of specific weights by arithmetic mean of scores assigned by experts.

\begin{tabular}{|l|c|c|c|c|c|c|}
\hline Indicator & S1 & S2 & $\ldots$ & SI & $\sum \mathbf{S}_{\mathbf{i}}$ & Sp. W. \\
\hline P1 Economy & $\mathrm{s}$ & $\mathrm{b}$ & $\mathrm{b}$ & $\mathrm{b}$ & $\sum \mathbf{S}_{\mathbf{i}}$ & $\mathrm{a} 1$ \\
\hline P2 Education & $\mathrm{s}$ & $\mathrm{s}$ & $\mathrm{s}$ & $\mathrm{s}$ & $\sum \mathbf{S}_{\mathbf{i}}$ & $\mathrm{a} 2$ \\
\hline P3 Power engineering & $\mathrm{s}$ & $\mathrm{s}$ & $\mathrm{s}$ & $\mathrm{s}$ & $\sum \mathbf{S}_{\mathbf{i}}$ & $\mathrm{a} 3$ \\
\hline P4 Environment & $\mathrm{s}$ & $\mathrm{s}$ & $\mathrm{s}$ & $\mathrm{s}$ & $\sum \mathbf{S}_{\mathbf{i}}$ & $\mathrm{a} 4$ \\
\hline P5 Finance & $\mathrm{s}$ & $\mathrm{s}$ & $\mathrm{s}$ & $\mathrm{s}$ & $\sum \mathbf{S}_{\mathbf{i}}$ & $\mathrm{a} 5$ \\
\hline P6 Fire safety & $\mathrm{s}$ & $\mathrm{s}$ & $\mathrm{s}$ & $\mathrm{s}$ & $\sum \mathbf{S}_{\mathbf{i}}$ & $\mathrm{a} 6$ \\
\hline P7 Guide & $\mathrm{s}$ & $\mathrm{s}$ & $\mathrm{s}$ & $\mathrm{s}$ & $\sum \mathbf{S}_{\mathbf{i}}$ & $\mathrm{a} 7$ \\
\hline P8 Health & $\mathrm{s}$ & $\mathrm{s}$ & $\mathrm{s}$ & $\mathrm{s}$ & $\sum \mathbf{S}_{\mathbf{i}}$ & $\mathrm{a} 8$ \\
\hline P9 Holidays & $\mathrm{s}$ & $\mathrm{s}$ & $\mathrm{s}$ & $\mathrm{s}$ & $\sum \mathbf{S}_{\mathbf{i}}$ & $\mathrm{a} 9$ \\
\hline P10 Security & $\mathrm{s}$ & $\mathrm{s}$ & $\mathrm{s}$ & $\mathrm{s}$ & $\sum \mathbf{S}_{\mathbf{i}}$ & $\mathrm{a} 10$ \\
\hline P11 Housing & $\mathrm{s}$ & $\mathrm{s}$ & $\mathrm{s}$ & $\mathrm{s}$ & $\sum \mathbf{S}_{\mathbf{i}}$ & $\mathrm{a} 11$ \\
\hline P12 Solid waste & $\mathrm{s}$ & $\mathrm{s}$ & $\mathrm{s}$ & $\mathrm{s}$ & $\sum \mathbf{S}_{\mathbf{i}}$ & $\mathrm{a} 12$ \\
\hline P13 Telecommunication & $\mathrm{s}$ & $\mathrm{s}$ & $\mathrm{s}$ & $\mathrm{s}$ & $\sum \mathbf{S}_{\mathbf{i}}$ & $\mathrm{a} 13$ \\
\hline P14 Transport & $\mathrm{s}$ & $\mathrm{s}$ & $\mathrm{s}$ & $\mathrm{s}$ & $\sum \mathbf{S}_{\mathbf{i}}$ & $\mathrm{a} 14$ \\
\hline P15 City planning & $\mathrm{s}$ & $\mathrm{s}$ & $\mathrm{s}$ & $\mathrm{s}$ & $\sum \mathbf{S}_{\mathbf{i}}$ & $\mathrm{a} 15$ \\
\hline P16 Wastewater & $\mathrm{s}$ & $\mathrm{s}$ & $\mathrm{s}$ & $\mathrm{s}$ & $\sum \mathbf{S}_{\mathbf{i}}$ & a16 \\
\hline P17 Water & $\mathrm{s}$ & $\mathrm{s}$ & $\mathrm{s}$ & $\mathrm{s}$ & $\sum \mathbf{S}_{\mathbf{i}}$ & $\mathrm{a} 17$ \\
\hline & - & - & - & $\mathrm{ij}$ & $\sum \sum$ & 1,000 \\
\hline
\end{tabular}

To determine the degree of expert coherence, it is recommended to use the concordance coefficient calculated by the formula (3):

$$
\mathrm{W}=\frac{12 \mathrm{~S}}{\mathrm{~m}^{2}\left(\mathrm{n}^{3}-\mathrm{n}\right)}
$$

where $m$ is the number of experts in the group, 
$\mathrm{n}$ is the number of factors,

$\mathrm{S}$ is the sum of squared differences of ranks (deviations from the mean).

To assess the indicators, it is important to develop an assessment scale, that can be based on the Likert scale, for example (Table 2).

Table 2. Gradation table.

\begin{tabular}{|c|l|}
\hline Score & \multicolumn{1}{|c|}{ Value } \\
\hline 1 & Absolutely bad condition in relation to the standard \\
\hline 2 & Poor condition with slight positive trends \\
\hline 3 & Satisfactory condition \\
\hline 4 & Good condition with prevailing positive trends \\
\hline 5 & Excellent condition \\
\hline
\end{tabular}

A clear advantage of the proposed system is its transparency, in other words, the developed theoretical approach ensures openness and accessibility for consumers and other stakeholders of information on the level of service delivery, and also creates an information base for the design of solutions to be implemented in order to improve society and the environment performance.

\section{Results}

The following qualimetric model was obtained as the result of conducted research:

$$
\begin{gathered}
K=0,070 \cdot P_{1}+0,095 \cdot P_{2}+0,049 \cdot P_{3}+0,099 \cdot P_{4}+0,021 \cdot P_{5}+0,052 \cdot P_{6}+0,043 \cdot P_{7}+ \\
+0,098 \cdot P_{8}+0,067 \cdot P_{9}+0,073 \cdot P_{10}+0,024 \cdot P_{11}+0,084 \cdot P_{12}+0,033 \cdot P_{13}+0,062 \cdot P_{14}+ \\
+0,023 \cdot P_{15}+0,023 \cdot P_{16}+0,086 \cdot P_{17}
\end{gathered}
$$

\section{Discussion}

Practical application can be illustrated for two Russian cities (Moscow and SaintPetersburg) (Table 3), for which experts have established the significance of the constituent indicators.

Table 3 illustrates the influence of specific weights' application: according to the average values, both cities have the same rating, and regarding the weights - the estimation is different. Thus, the rating of Saint-Petersburg is higher.

The advantage of the proposed qualimetric model $(1,4)$ is the simplicity of the approach, which causes the greatest popularity of the model. However, we can mention the following drawbacks of the approach:

$\checkmark$ leveling the dynamics of indicators, the presence of mutual compensation of indicators, in other words, a lag in one indicator can be compensated by the faster growth of another;

$\checkmark$ subjectivism and errors in determining the weight coefficients that depend on the expert's opinion;

$\checkmark$ groundlessness of the additivity assumption of all the component indicators.

At present, the most progressive approach to qualimetric estimation is based on the use of vector representation and multiparametric analysis, for example, the hierarchy method or models based on the Kemeni distance between the estimated object (variant) and some ideal (normative) [7]. 
Table 3. The analysis of cities by the score system, according to the weights.

\begin{tabular}{|l|c|c|c|c|}
\hline & \multicolumn{2}{|c|}{ Moscow } & \multicolumn{2}{c|}{ Saint-Petersburg } \\
\hline \multicolumn{1}{|c|}{ Indicator } & $\begin{array}{c}\text { Not regarding } \\
\text { Sp. W. }\end{array}$ & $\begin{array}{c}\text { Regarding } \\
\text { Sp. W. }\end{array}$ & $\begin{array}{c}\text { Not regarding } \\
\text { Sp. W. }\end{array}$ & $\begin{array}{c}\text { Regarding } \\
\text { Sp. W. }\end{array}$ \\
\hline P1 Economy & 5 & 0,35 & 4 & 0,28 \\
\hline P2 Education & 5 & 0,48 & 5 & 0,48 \\
\hline $\begin{array}{l}\text { P3 Power } \\
\text { engineering }\end{array}$ & 4 & 0,20 & 3 & 0,15 \\
\hline P4 Environment & 3 & 0,30 & 5 & 0,50 \\
\hline P5 Finance & 4 & 0,08 & 3 & 0,06 \\
\hline P6 Fire safety & 3 & 0,16 & 4 & 0,21 \\
\hline P7 Guide & 4 & 0,17 & 4 & 0,17 \\
\hline P8 Health & 3 & 0,29 & 5 & 0,49 \\
\hline P9 Holidays & 4 & 0,27 & 4 & 0,27 \\
\hline P10 Security & 4 & 0,22 & 5 & 0,36 \\
\hline P11 Housing & 4 & 0,10 & 4 & 0,10 \\
\hline P12 Solid waste & 4 & 0,13 & 4 & 0,33 \\
\hline $\begin{array}{l}\text { P13 } \\
\text { Telecommunication }\end{array}$ & 4 & 0,25 & 3 & 0,10 \\
\hline P14 Transport & 5 & 0,11 & 3 & 0,18 \\
\hline P15 City planning & 4 & 0,09 & 4 & 0,07 \\
\hline P16 Wastewater & 5 & 0,43 & 5 & 0,43 \\
\hline P17 Water & $\mathbf{4}$ & $\mathbf{4}$ & $\mathbf{4}, 30$ \\
\hline Total & 4 & & \\
\hline
\end{tabular}

\section{Conclusion}

Urban indicators should cover the full range of sustainable development characteristics proposed in international standards to measure their performance in order to ensure an integrated and holistic approach to sustainable development and quality of life.

For the analysis, it is necessary to use complex indicators that allow:

1) measurement of the level of development and quality of life in dynamics;

2) wide range indicator analysis;

3 ) exchange of the best practices and the development of management decisions.

\section{References}

1. United Nations. Glossary of Environmental Statistics, https://unstats.un.org/unsd/publication/SeriesF/SeriesF_67R.pdf

2. Guiding Principles for Sustainable Development of the European Continent (Strasbourg, 2002) 
3. Standard ISO /TC 268 Sustainable development of the community, http://www.iso.org/iso/ru/home/standards_development/list_of_iso_technical_committ ees/iso_technical_committee.htmcommid=656906

4. Standard ISO 37120:2014 Sustainable development of communities - Indicators for city services and quality of life

5. P.I. Burak, T.I. Zvorikina, Economics of quality, 2(6) (2014) http://eqjournal.ru/archive/2014/номер-2(6)/

6. E.A. Gorbashko, Quality management (Publishing House Yurayt, 2012)

7. T.I. Leonova, U.A. Kalazhokova, Fundamental Research 6(1), 143-147 (2015)

8. V.V. Okrepilov, Quality management, volume 2 (Science, SPb, 2007)

9. V.V. Okrepilov, Economics of quality (Science, SPb, 2011)

10. S.N. Kuzmina, A.V. Babkin, Scientific and technical statements of SPbSPU. Economic sciences 6, 35-67 (2017) 